\title{
Dobutamine stress-induced ischemic right ventricular dysfunction in patients with three-vessel coronary artery disease
}

Ramin Khameneh Bagheri ${ }^{1}$, Mostafa Ahmadi ${ }^{1}$, Hedyeh Alimi ${ }^{1}$, Laya Valaee ${ }^{2}$, Toktam Sahranavard ${ }^{3}$, Mohammad Sobhan Sheikh Andalibi ${ }^{3}$

${ }^{1}$ Cardiologist, Assistant Professor, Cardiovascular Research Center, Department of Cardiology, Qaem Hospital, Mashhad University of Medical Sciences, Mashhad, Iran

${ }^{2}$ M.D., Resident of Cardiology, Cardiovascular Research Center, Student Research Committee, School of Medicine, Imam Reza Hospital, Mashhad University of Medical Sciences, Mashhad, Iran

${ }^{3}$ M.D., Cardiovascular Research Center, Student Research Committee, School of Medicine, Mashhad University of Medical Sciences, Mashhad, Iran

\section{Type of article: Original}

\begin{abstract}
Background: Dobutamine stress echocardiography (DSE) is a non-invasive technique to detect coronary artery diseases (CAD). There are limited studies on evaluation of the right ventricular function by stress echocardiography. The appropriate evaluation of RV function and early diagnosis of its failure can help to improve outcomes for the patients undergoing cardiac surgery.

Objective: To determine right ventricular dysfunction in patients with three-vessel CAD by using DSE.

Methods: This cross-sectional study was among 13 patients who were candidates for coronary artery bypass grafting (CABG) referred to Ghaem Hospital, Mashhad, Iran; from September 2015 to May 2016. After a physical examination and initial measures, DSE was performed and echocardiographic parameters were recorded by a cardiologist. Paired-samples t-test was performed using SPSS Software v.16.0 for data analysis.

Results: The study included 13 patients $(9$ males) with a mean age of $65.4 \pm 7.6$ years. The mean of TAPS was $16.9 \pm 4.5 \mathrm{~mm}$ and $15.7 \pm 2.9 \mathrm{~mm}$ before and after stress echocardiography, respectively $(\mathrm{p}=0.69)$. Systolic right ventricular (SRV) peak increased from before DSE compared with after DSE $(8.0 \pm 2.2 \mathrm{vs} .13 .7 \pm 4.2 \mathrm{~mm} / \mathrm{s}$, $\mathrm{p}<0.001)$. In addition, after dobutamine injection, right ventricular $(\mathrm{RV})$ cardiac output decreased in 7 patients and one patient was affected by post-ejection shortening.

Conclusion: It seems that TAPS and RV cardiac output after injection of dobutamine, can be used as markers for the recognition of ischemic RV dysfunction.

Keywords: Right ventricular dysfunction, Coronary artery disease, Dobutamine, Stress echocardiography
\end{abstract}

\section{Introduction}

Cardiovascular disease (CVD) is the leading cause of mortality, morbidity, and disability around the world (1). According to the increasing prevalence of CVD, diagnosis, timely treatment, and prevention of the complications are very substantial (2). It is important to identify symptomatic patients with obstructive coronary artery disease (CAD), especially the patients with left main and/or three-vessel CAD, due to appropriate medical treatment accompanied with revascularization result in the improvement of symptoms and patient's prognosis (3-5). Guidelines suggested stress echocardiography (SE) as a primary procedure for evaluation of established or suspected CAD patients (6). Dobutamine stress echocardiography (DSE) is a non-invasive technique to detect CVD (7). In other words, DSE is widely used in the evaluation of myocardial structure and function under physiological and

\section{Corresponding author:}

Dr. Mohammad Sobhan Sheikh Andalibi, Cardiovascular Research Center, Student Research Committee, School of Medicine, Mashhad University of Medical Sciences, Mashhad, Iran.

Tel:+989151063990, Email: andalibims891@mums.ac.ir and mssha96@gmail.com

Received: June 09, 2017, Accepted: March 04, 2018, Published: May 2018

iThenticate screening: December 08, 2017, English editing: March 18, 2018, Quality control: April 14, 2018

This article has been reviewed / commented by three experts

(C) 2018 The Authors. This is an open access article under the terms of the Creative Commons Attribution-NonCommercialNoDerivs License, which permits use and distribution in any medium, provided the original work is properly cited, the use is non-commercial and no modifications or adaptations are made. 
pharmacological stress conditions $(6,8)$. In the recent years, the use of this technique has been increased in challenging diagnostic cases due to its perceptual versatility and vast application. SE is simple and available, but it is necessary to follow its training recommendations. Therefore, the application of SE may be less dependent on the experience and interpretation of the operator (6). To detect CAD and its effect on myocardial function, some noninvasive techniques including stress echocardiography, thallium scintigraphy, and dobutamine stress echocardiography are used. Despite their ability to manifest various patterns of left ventricular dysfunction, this procedure could not show the severity of right ventricular (RV) ischemic dysfunction (9). Traditionally, it is believed that right heart only serves as a passive conduit. But recent studies showed that right heart has a crucial role in adequate pulmonary perfusion pressures under various conditions (8). Due to the geometry and kinematics complexity of the assessment of right ventricular (RV) function by SE, it has not been well investigated so far. Therefore, there was no sufficient information about the methodology and quantitating RV function during stress echocardiography (10). As a result, ventricular dysfunction and cardiac failure impose an economic burden on the healthcare systems, especially in developing countries. The appropriate evaluation of RV function and early diagnosis of its failure can lead to timely intervention, reduced economic costs and improvement of outcomes in the acutest patients undergoing coronary artery bypass graft $(\mathrm{CABG})$ surgery $(11,12)$. Therefore, the aim of this study was to determine ischemic right ventricular dysfunction in patients with three-vessel CAD by using DSE.

\section{Material and Methods}

\subsection{Study Design and setting}

This cross-sectional study was among patients (n:13) who were candidates of coronary artery bypass grafting (CABG) referred to Ghaem Hospital, Mashhad, Iran; from September 2015 to May 2016.

\subsection{Participants and sampling}

Patients with documented 3-vessel CAD and right coronary involvement were included in this study. The cases were diagnosed by a cardiologist during angiography ( $>50 \%$ stenosis). Patients with any complication during DSE including ventricular and supraventricular tachycardia, monomorphic and polymorphic ventricular and supraventricular extra-systolic beats, AV-block and also patients with the history of cardiac disorders such as right ventricular infarction, any other right heart involvements, pulmonary emboli, pulmonary hypertension and regional wall motion abnormalities of RV and cases affected by chronic obstructive pulmonary disease, were excluded from the study. Cases were enrolled to the study using the purposive sampling method.

\subsection{Echocardiography}

After receiving written consent of all patients, echocardiography was performed with VIVID S5 ${ }^{\text {TM }}$ (General Electric Healthcare, U.S.A) echocardiogram system. Dobutamine was injected $(5 \mathrm{mcg} / \mathrm{kg} / \mathrm{min})$ via a pump and increased in intervals of three minutes to $10,20,30$ and $40 \mathrm{mcg} / \mathrm{kg} / \mathrm{min}$ to reach the desired heart rate $(85 \%$ predicted maximum). All echocardiographic parameters (standard and function of right ventricular) were determined. To prevent inter-observer variation, all echocardiographic assessments were done by two cardiologists. During DSE, acute chest pain, hypertension, arrhythmia, or any signs indicating the necessity to stress echocardiography interruption occurred, stress echocardiography was suspended, and consequently, the patient was excluded.

\subsection{Statistical analysis}

All analyses were carried out using SPSS 16.0 (SPSS Inc., Chicago, IL, USA). Categorical measurements were reported as number and percentage. Quantitative measurements were reported as the mean \pm SD. KolmogorovSmirnov test was used to show the normal distribution of quantitative measurements. Paired-samples t-test was used for comparing the echocardiographic parameters before and after the DSE test. Statistical significance was assessed at a level of 0.05 (two-tailed) for all analyses.

\subsection{Research ethics}

All of the procedure stages, information, possible side effects and context of treatment were explained to the patients and all patients signed written informed consent to participate in the study. In addition, our study was done according to the guideline of the Declaration of Helsinki and also approved by the Ethical Committee of Mashhad University of Medical Sciences, Mashhad, Iran (no: 930756). 


\section{Results}

\subsection{Demographic characteristics}

As shown in Table 1 , this study included 13 patients who were CABG ( 9 male / 4 female) with the mean age of $65.4 \pm 7.6$ years old. The maximum age of participants was 82 years and the minimum age was 56 years. Two patients (15.4\%) reported angina, but $11(84.6 \%)$ patients did not have the mentioned cardiac symptom. One patient (7.7\%) had post-ejection shortening at the end of stress echocardiography (after ejecting Dobutamine). RV cardiac output decreased in 7 patients $(53.8 \%)$ at the end of stress echocardiography.

Table 1. Demographic and characteristics of the patients.

\begin{tabular}{|l|l|}
\hline Variable & $\mathrm{n} \mathrm{( \% )*}$ \\
\hline Male & $9(69.2)$ \\
\hline Age* (year) & $65.4 \pm 7.6$ \\
\hline Angina & $2(15.4)$ \\
\hline RV inlet diameter* $(\mathrm{mm})$ & $32.7 \pm 5.9$ \\
\hline Post injection shortening & $1(7.7)$ \\
\hline TAPS before DSE $(\mathrm{mm})^{*}$ & $16.9 \pm 4.5$ \\
\hline TAPS after DSE $(\mathrm{mm})^{*}$ & $15.7 \pm 2.9$ \\
\hline RV peak systolic before DSE $(\mathrm{cm} / \mathrm{s})^{*}$ & $8.0 \pm 2.2$ \\
\hline RV peak systolic after DSE $(\mathrm{cm} / \mathrm{s})^{*}$ & $13.7 \pm 4.2$ \\
\hline Reduced RV output after DSE & $7(53.8)$ \\
\hline Wall motion score index* & $1.3 \pm 0.23$ \\
\hline
\end{tabular}

* Quantitative parameters were expressed as mean \pm standard deviation; RV: right ventricle, DSE: Dobutamine stress echocardiography, TAPS: Tricuspid annular plane systolic excursion

\subsection{Echocardiographic parameters}

The mean of RV inlet diameter before injecting Dobutamine was $32.7 \pm 5.9 \mathrm{~mm}$ (ranged from 22 to $47 \mathrm{~mm}$ ) in participants (Table 1). The mean of Systolic right ventricular (SRV) peak before and after DSE was significantly different ( $8.0 \pm 2.2$ vs. $13.7 \pm 4.2, \mathrm{p}<0.001$. However, there was no significant difference between the tricuspid annular plane systolic excursion (TAPS) mean before and after the injection of Dobutamine) $16.9 \pm 4.5$ vs. $15.7 \pm 2.9, \mathrm{p}=0.69$ ) (Figure 1).

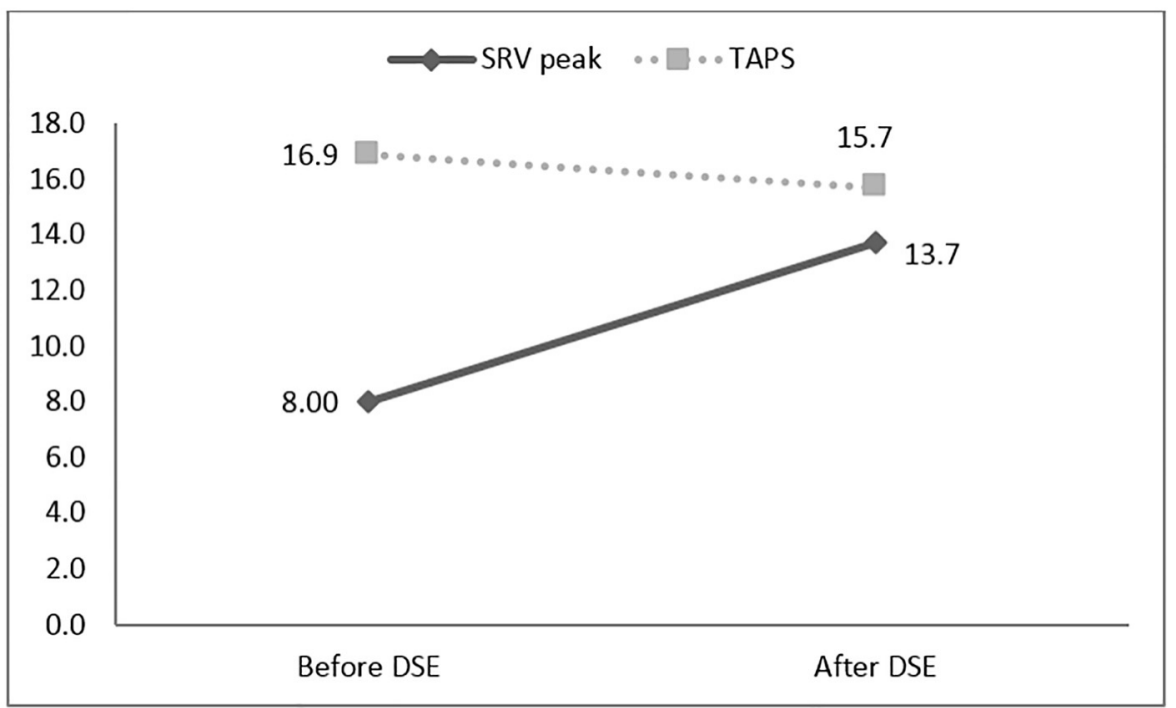

DSE: Dobutamine stress echocardiography; TAPS: tricuspid annular plane systolic excursion; SRV: systolic right ventricular

Figure 1. Comparing of systolic right ventricular peak and tricuspid annular plane systolic excursion before and after the stress echocardiography. 


\section{Discussion}

This study was conducted to evaluate right ventricular ischemia through using DSE in three-vessel CAD. The results showed that TAPS and RV cardiac output can be used to detect right ventricular dysfunction after Dobutamine injection. We studied five major echocardiographic parameters. Three of them demonstrated the RV state (TAPS, SRV, and RV cardiac output), and two parameters indicated the left ventricular function. According to our trend, we focused on the RV parameters. One of the most important issues before and after coronary artery bypass surgery is the evaluation of cardiac ventricles, particularly the right ventricle. Nevertheless, the exact mechanism of contractile dysfunction and left ventricular filling after CABG is not specified (13). Right ventricular dysfunction is a known complication that rapidly appears after cardiac surgery. So identifying the patients with RV dysfunction before the operation is an efficient factor in patients' prognosis $(13,14)$. Many studies have concentrated on left ventricle function before and after $\mathrm{CABG}$, but not right ventricle function. The probable reason for the limited studies is the complex anatomy of the right ventricle. Therefore, to date, no gold standard has been set to evaluate the right ventricular function by echocardiography (15). Recording of TAPS is a practical and easy procedure in many patients. However, limited studies considered TAPS as a benchmark in identifying the right ventricular dysfunction before CABG $(7,9,10,16)$. A few studies have shown that the motion of tricuspid valve decreases during systole immediately after CABG. So it is a useful criterion in right ventricular dysfunction $(17,18)$. In this present study, the mean of TAPS did not show any RV dysfunction. Interestingly, it reached to $15.7 \mathrm{~mm}$ after injecting Dobutamine, which was in the range of RV dysfunction. Although the changes were not statistically significant, it was probably due to the small sample size of this study. It is important to note that these changes would be clinically meaningful and decisive. Of note, in patients who have undergone $\mathrm{CABG}$, in the case of preserved left ventricular function with reduced right ventricular function, an imbalance at the right to left blood flow might be seen. So, the study on right ventricle function before bypass surgery is consequential and TAPS can be used as possible criteria. The other point in this study was the SRV changes. The mean of SRV was 8 and $13.7 \mathrm{~mm} / \mathrm{s}$ before and after injection of Dobutamine, respectively, which meant no RV dysfunction. In other words, TAPS represents the tricuspid RV dysfunction and SRV reveals a free wall of the right ventricle. In a study, the normal range of estimated SRV pressure at peak exercise during exercise stress echocardiography (ExECHO) was evaluated. The results showed that the SRV should not increase more than $24.6 \mathrm{mmHg}$ in men and $24.5 \mathrm{mmHg}$ in women, respectively. This value is calculated as the increase in pressure SRV plus $2 x S D$ of pressure SRV. The maximum amount of SRV should be $57.4 \mathrm{mmHg}$ in men and $58 \mathrm{mmHg}$ in women. If one of them increases, the SRV response to the test should be considered abnormal (16). We found after Dobutamine infusion, the RV cardiac output in about half of the patients decreased, which showed the considerable role of Dobutamine in determining RV dysfunctions in 3-vessel CAD patients. In this study, the mean of RV inlet diameter obtained $32.5 \mathrm{~mm}$. Based on existing criteria, the inlet diameter of RV that is greater than $35 \mathrm{~mm}$ shows dilated RV. In this study, RV size in most patients was in normal range. In a prior study, the RV function was evaluated during SE. for this purpose; the ejection fraction of global RV function was measured. Then radial velocity, circumferential strain and strain rate was used in four parts of RV to evaluate the regional RV function. Finally, they concluded that the quantitative evaluation and regional and global RV is possible during SE and by VVI analysis (10). Although some studies reported the possible side effects of DSE including tachycardia, chest pain, st-segment elevation and myocardial ischemia (19), we have observed no side effect during DSE. The study included 13 patients and the sample size was small compared with similar studies, due to time limitations. However, the gender distribution was proper in our study and $31 \%$ of the patients were female while in a similar study only $10 \%$ of patients were female (9). The mean age of our patients was nearly similar to other studies. We reported it as 65 years and in other studies, it was 50-60 years $(7,9,10,16)$.

\section{Limitations}

It was a single center study and the sample size was small and it was similar to a pilot study. According to these results, we recommend a multicenter study with a higher sample size. There is no control group in our study, thus generalizability of the findings is not easily possible. Therefore, further studies are needed by taking a control group. We also suggest that in future investigations, it would be better to assess more echocardiographic variables regarding RV dysfunction.

\section{Conclusions}

This study suggested that TAPS and RV cardiac output, after Dobutamine injection, can be used as markers for the recognition of ischemic RV dysfunction. Also, there is a need for designing a study which compares the most useful imaging methods for indicating RV dysfunction. Prospective large-scale and randomized clinical trials are suggested to support more evidence-based treatment strategies for future studies. 


\section{Acknowledgments:}

The authors would like to thank all the subjects participating in the current study. This study was supported by Mashhad University of Medical Science (MUMS), Iran. The results presented in this work have been taken from Dr. Seyed Javad Masoumi's thesis in MUMS, with the following ID number: 930756.

\section{Conflict of Interest:}

There is no conflict of interest to be declared.

Authors' contributions:

All authors contributed to this project and article equally. All authors read and approved the final manuscript.

\section{References:}

1) Ebrahimi M, Kazemi-Bajestani SM, Ghayour-Mobarhan M, Ferns GA. Coronary artery disease and its risk factors status in iran: a review. Iran Red Crescent Med J. 2011; 13(9): 610-23. PMID: 24069531, PMCID: PMC3779358.

2) Perk J, De Backer G, Gohlke H, Graham I, Reiner Ž, Verschuren M, et al. European Guidelines on cardiovascular disease prevention in clinical practice (version 2012) The Fifth Joint Task Force of the European Society of Cardiology and Other Societies on Cardiovascular Disease Prevention in Clinical Practice (constituted by representatives of nine societies and by invited experts)Developed with the special contribution of the European Association for Cardiovascular Prevention \&amp; Rehabilitation (EACPR). European Heart Journal. 2012; 33(13): 1635-701. doi: 10.1093/eurheartj/ehs092.

3) Wijns W, Kolh P, Danchin N, Di Mario C, Falk V, Folliguet T, et al. Guidelines on myocardial revascularization. Eur Heart J. 2010; 31(20): 2501-55. doi: 10.1093/eurheartj/ehq277. PMID: 20802248.

4) Jeremias A, Kaul S, Rosengart TK, Gruberg L, Brown DL. The impact of revascularization on mortality in patients with nonacute coronary artery disease. Am J Med. 2009; 122(2): 152-61. doi: 10.1016/j.amjmed.2008.07.027. PMID: 19185092.

5) Dharampal AS, Papadopoulou SL, Rossi A, Meijboom WB, Weustink A, Dijkshoorn M, et al. Diagnostic performance of computed tomography coronary angiography to detect and exclude left main and/or threevessel coronary artery disease. Eur Radiol. 2013; 23(11): 2934-43. doi: 10.1007/s00330-013-2935-6. PMID: 23812241.

6) Picano E, Pellikka PA. Stress echo applications beyond coronary artery disease. Eur Heart J. 2014; 35(16): 1033-40. doi: 10.1093/eurheartj/eht350. PMID: 24126880.

7) Elsherbiny IA. The significance of $\mathrm{E} / \mathrm{E}^{\prime}$ to detect coronary artery disease during dobutamine stress echocardiography. The Egyptian Heart Journal. 2012; 64(1): 21-6. doi: 10.1016/j.ehj.2011.09.003.

8) Chenzbraun A. Non-ischaemic cardiac conditions: role of stress echocardiography. Echo Res Pract. 2014; 1(1): R1-7. doi: 10.1530/erp-14-0030. PMID: 26693299, PMCID: PMC4676472.

9) O'Sullivan CA, Duncan A, Daly C, Li W, Oldershaw P, Henein MY. Dobutamine stress-induced ischemic right ventricular dysfunction and its relation to cardiac output in patients with three-vessel coronary artery disease with angina-like symptoms. Am J Cardiol. 2005; 96(5): 622-7. doi: 10.1016/j.amjcard.2005.04.031. PMID: 16125482 .

10) Yang HS, Mookadam F, Warsame TA, Khandheria BK, Tajik JA, Chandrasekaran K. Evaluation of right ventricular global and regional function during stress echocardiography using novel velocity vector imaging. Eur J Echocardiogr. 2010; 11(2): 157-64. doi: 10.1093/ejechocard/jep190. PMID: 19946117.

11) Yuan Z, He C, Yan S, Huang D, Wang H, Tang W. Acupuncture for overactive bladder in female adult: a randomized controlled trial. World J Urol. 2015; 33(9): 1303-8. doi: 10.1007/s00345-014-1440-0. PMID: 25399241.

12) Cook C, Cole G, Asaria P, Jabbour R, Francis DP. The annual global economic burden of heart failure. International Journal of Cardiology. 2014; 171(3): 368-76. doi: 10.1016/j.ijcard.2013.12.028.

13) Hedman A, Alam M, Zuber E, Nordlander R, Samad BA. Decreased right ventricular function after coronary artery bypass grafting and its relation to exercise capacity: a tricuspid annular motion-based study. J Am Soc Echocardiogr. 2004; 17(2): 126-31. doi: 10.1016/j.echo.2003.10.023. PMID: 14752486.

14) Stein KL, Breisblatt W, Wolfe C, Gasior T, Hardesty R. Depression and recovery of right ventricular function after cardiopulmonary bypass. Crit Care Med. 1990; 18(11): 1197-200. PMID: 2225885.

15) Haber I, Metaxas DN, Geva T, Axel L. Three-dimensional systolic kinematics of the right ventricle. Am J Physiol Heart Circ Physiol. 2005; 289(5): H1826-33. doi: 10.1152/ajpheart.00442.2005. PMID: 15964922. 
16) Armstrong DW, Matangi MF. Estimated right ventricular systolic pressure during exercise stress echocardiography in patients with suspected coronary artery disease. Can J Cardiol. 2010; 26(2): e45-9. PMID: 20151058, PMCID: PMC2851391.

17) Wranne B, Pinto FJ, Hammarstrom E, St Goar FG, Puryear J, Popp RL. Abnormal right heart filling after cardiac surgery: time course and mechanisms. Br Heart J. 1991; 66(6): 435-42. PMID: 1772709, PMCID: PMC1024818.

18) Polak JF, Holman BL, Wynne J, Colucci WS. Right ventricular ejection fraction: an indicator of increased mortality in patients with congestive heart failure associated with coronary artery disease. J Am Coll Cardiol. 1983; 2(2): 217-24. PMID: 6306086.

19) Mertes H, Sawada SG, Ryan T, Segar DS, Kovacs R, Foltz J, et al. Symptoms, adverse effects, and complications associated with dobutamine stress echocardiography. Experience in 1118 patients. Circulation. 1993; 88(1): 15-9. doi: 10.1161/01.cir.88.1.15. 